\title{
14. Is literacy what we need in an unequal data society?
}

\author{
Lulu Pinney
}

\begin{abstract}
Having the skills and awareness to make sense of data visualizations has become a contributing factor in determining who gets to participate in our data-driven society. Initiatives that seek to enable people to make sense of some aspect of our digital, datafied worlds are often described in terms of literacy. However, taking a closer look at different usages of literacy across academia, policy, and practice reveals different notions of power embedded in different populations' implicit understanding of the term. Situated in the emerging field of critical data studies, the field that is concerned with understanding data's role in reproducing and creating social inequalities, this is a conceptual chapter that asks how useful literacy is in this context.
\end{abstract}

Keywords: Know-how; Expertise; Everyday; Data justice; Datafication; Participation

\section{Introduction}

In this digital age, information and data are presented to us more and more often, on a range of subject matter, from many sources, across a variety of different channels, in different formats, relating to most aspects of our lives. This presents us with many things of which we need to make sense. Correspondingly, you do not have to look far to find a project or initiative offering to teach us how to make sense of some aspect of our digital, datafied worlds. Often these projects' descriptions include the term literacy, and examples can be found across academia, practice, and policy. One definition of literacy, from the United Nations Educational, Scientific and Cultural Organization (UNESCO), is as follows:

Engebretsen, M. and H. Kennedy (eds.), Data Visualization in Society. Amsterdam: Amsterdam University Press, 2020 DOI 10.5117/9789463722902_CH14 
Literacy is defined as the ability to identify, understand, interpret, create, communicate and compute using printed and written materials associated with diverse contexts. Literacy involves a continuum of learning in enabling individuals to achieve their goals, develop their knowledge and potential and participate fully in community and society. (UNESCO, 2005)

However, as a concept with a long history, literacy has come to mean different things to different people in different contexts.

The emerging academic field of critical data studies is concerned with social inequalities that are created and reproduced as a consequence of the widespread production, circulation, and uses of data. With data increasingly being 'mobilized graphically' (Gitelman \& Jackson, 2013, p. 12), the relationship between power and data visualizations in society is also of critical interest, including the inequality that results from not being able to make sense of data visualizations.

This chapter is a conceptual one. It explores different notions of power embedded in implicit understandings of terminology used in projects that seek to enable people to make sense of the data society they live in, in the context of the inequalities that result from that same data society. In doing this it has been helpful to distinguish between literacy as a concept and literacy as a term. A dictionary definition (OED Online, 2018) of both words is provided here:

Concept: a general idea or notion, a universal; a mental representation of the essential or typical properties of something, considered without regard to the peculiar properties of any specific instance or example. Term: A word or phrase used in a precise sense in a particular subject or field, or by a particular group of people; a technical expression; a piece of jargon.

I argue that literacy is useful as a concept because it enables those affected by inequality to ask critical questions. However, as a term, I find its use for engaging populations is limited.

\section{The concept of literacy is useful for researching an unequal data society}

Referring to the world we live in as a 'data society' is to acknowledge not only the ubiquitous presence of data in society but also that these data have an impact on our worlds and our experiences of living in them. The 
widespread use of digital technology means we are creating data much of the time, with examples including what we discuss on social media and with whom, how many kilometres we run and where, or where we use our credit cards and what we buy. The impacts of data like these on our lives depend on the assumptions, biases, methods, and motivations of the organizations and individuals who collect and use our data (boyd \& Crawford, 2012). Whoever collects the data and decides how they are going to be used is in a position of power, whether or not they realize it, relative to the people whose data are collected. This has led scholars to ask questions about the relationship of digital data to issues such as surveillance, privacy, exploitation, discrimination, and exclusion that can result from such a data society (e.g. boyd \& Crawford, 2012; Eubanks, 2018; Noble, 2018). These issues are the focus of the field of critical data studies, which interrogates data's contribution to social inequality either through reproducing existing inequalities or creating new ones (Kennedy, 2018).

Data visualizations also contribute to inequality in our data society. Boyd and Crawford (2012) argue that, alongside having access to data, having the skills to work with data is also a factor in determining the societal divides that emerge. Gitelman and Jackson (2013) observe that 'data are mobilized graphically' (p. 12), that is to say that to be useful to us, data are usually represented visually. Therefore, whether or not individuals and institutions have the skills to work with data visualizations also impacts who gets to participate in a data society (Kennedy \& Hill, 2017).

What is known about skills for working with data visualizations is that they are diverse and, in the context of social inequality, must include critical awareness as well as practical dimensions. Though there is no definitive list of skills for working with data visualizations, doing so involves the following steps, each one contributing to the end-to-end production of any data visualization: data creation, processing, and distribution; visual representation and design of data; and finally, data visualization distribution and then viewing. In addition to the practical skills needed to perform each of these steps, the importance of critical skills is highlighted by Gray et al. (2016), who illustrate the social and cultural factors that lead to mediation in every step in the production of a data visualization. These factors include the people, institutions, infrastructure, tools, methods, usage, aesthetics, and contexts involved, all of which are shaped by human decision-making, bias, and assumptions. A further factor to consider is that this mediation is obscured by both the seemingly simple outward appearance of data visualizations and the popular belief that data visualizations, like the data on which they are based, are objective (Kennedy \& Hill, 2016). It can be seen 
that on top of diverse practical skills, the social and cultural provenance of data visualizations demands a critical awareness of data visualization as a practice (Gray et al., 2016; Kennedy \& Hill, 2016) without which Kennedy and Hill (2016) argue, in summary, data visualizations will continue to 'privilege certain viewpoints, perpetuate existing power relations and create new ones' (p. 5). It is also for this reason that researchers interested in the role of data visualizations in society often talk about the skills and awareness to make sense of data visualizations, inviting consideration of both the practical and critical dimensions, rather than working with data visualizations, a notion which is more commonly associated with practical, operational, or technical skills.

There is a significant body of work around how to make sense of data visualizations cognitively and perceptually (Card, Mackinlay, \& Shneiderman, 1999; Ware, 2012) and this knowledge underpins much popular, practical guidance for working with data visualizations (Cairo, 2013; Few, 2013; Ware, 2012). However, this work often treats data visualizations as isolated texts that are independent of their provenance, the person who is looking at them, and the context in which this happens. Overlooking these sociocultural factors limits the possibility of finding out how the skills and awareness needed for making sense of data visualizations impact power relations and participation in a data society. This is where the concept of literacy can provide a useful framework, and there are two key features that make it so, which I discuss next: firstly, literacy as a social practice; and, secondly, literacy as an enabler of social change.

Thinking of literacy as a social practice is to understand that literacy is relevant to everyone, practised in different aspects of our everyday lives, and dependent on both context and individual (Barton \& Hamilton, 1998; Street, 1984). This concept, developed by New Literacy Studies scholars over the last 40 years, has displaced the 'autonomous model' (Street, 1984), a traditional approach to literacy that Street criticized for characterizing literacy as a set of neutral, technical, decontextualized skills that, if an individual was in possession of them-or literate-could be deployed regardless of time, place, or purpose. The usefulness of thinking of literacy as a social practice for research into the skills and awareness needed for making sense of some aspect of modern society against a backdrop of inequality can be illustrated from literatures on visual literacy, media literacy, information literacy, data literacy, and digital literacy, five literacy fields that relate to data visualization literacy. The common goal of literacy initiatives across these fields is enabling people to be both active users and producers of visuals, media, information, data, or digital media respectively. However, 
they all also emphasize the importance of doing these things critically, by taking into account the broader contexts in which users and producers are operating. This results in a recognition of the need for a wide range of multidimensional skills, critical as well as practical. The extent of any individual's performance of such skills can be modelled on a continuum and will fluctuate depending on the context in which the skills are being drawn (Avgerinou \& Pettersson, 2011; Bassett, Fotopoulou, \& Howland, 2013; Letouzé et al., 2015; Potter, 2005; SCONUL, 2011). Understanding literacy as a social practice in this way allows researchers to account for the influence of sociocultural factors on the skills and awareness needed for making sense of data visualizations in an unequal data society, that is to say to include the critical dimension necessary for raising questions around power in the context of inequality. In this way the concept of literacy is useful to researchers.

The second useful feature of the concept of literacy is as an enabler of social change. This emancipatory dimension of the concept of literacy is exemplified by the work of Paolo Freire, who understood literacy as the ability to make sense of the world in which we live (Freire, 1996). He believed and practised the idea that it is only by enabling people to identify the power structures regulating their lives that they can challenge them. This is an approach that values and builds on the knowledge and experience of those adversely affected by inequality. This understanding of literacy builds on the first by also raising questions around power, but then goes further by also understanding it as enabling those affected by power imbalances to ask critical questions. In this way the concept of literacy has the potential to also be useful to those who experience inequality in a data society.

Many scholars share this emancipatory understanding of the concept of literacy because it is useful for researching how sense is made of some aspect of society in the context of social inequality. Examples relevant to the field of critical data studies can be illustrated through the work of several authors of chapters in this book: D'Ignazio and Bhargava do ongoing data literacy work with communities, including their introductory web tool DataBasic (D'Ignazio \& Bhargava, 2016) and the Data Culture Project (Bhargava, 2018); Tønnessen is researching visual-numeric literacy in secondary schools (this volume) through the Innovative Data Visualization and Visual-Numeric Literacy (INDVIL) project of which she and this book are a part; Gray et al. (2018) recently called for data infrastructure literacy as 'the ability to account for, intervene around and participate in the wider socio-technical infrastructures through which data are created, stored and analysed' (p. 1); Archer and Noakes are researching data visualization's role in academic 
literacies in higher education (this volume); Kennedy, Hill, and colleagues' Seeing Data project (Kennedy et al., n.d.) was designed around developing the general public's visualization literacy; and Feigenbaum and colleagues' (2016) Datalabs project sought to 'establish a sustainable training model for data literacy, data-driven research and data storytelling' in journalism education (p. 62). All of these scholars, to a greater or lesser degree, have understood the concept of literacy as both a social practice and an enabler of social change. That is to say, this is the understanding they implicitly associate with literacy, and is why literacy is useful in their work. What none of them do, however, is consider that their implicit understanding of literacy is not necessarily the same as everyone else's.

\section{Literacy does not mean the same thing to everyone}

Literacy, both as a term and as a concept, is widely used beyond the examples just given, in academia as well as in practice, policy, and everyday life. This includes usage as a term in its own right, literacy, as well as part of compound terms, for example digital literacy or visualization literacy. Some scholars from the academic disciplines of information, computer, and cognitive science research visualization literacy (Boy, Rensink, Bertini, \& Fekete, 2015; Lee et al., 2016). In practice, data literacy initiatives are emerging all the time, with online examples including datatothepeople.org and dataliteracy.fit. There are policies for developing media, information, and digital literacies at UK national and European scales (Department for Digital, Culture, Media, \& Sport, 2017; Vuorikari, Punie, Carretero, \& Van Den Brande, 2016), with data literacy beginning to be talked about in the context of the UK government's own use of data (Duhaney, 2018; Knight, 2018). In the news, Kate Winslet is warning of the 'shame' of illiteracy' for young women who cannot read or write (Coughlan, 2018). In my inbox, a former client recently asked if I can recommend any data literate graphic designers.

While the term literacy is widely used, the implicit understandings that different people associate with it vary. To consider its different meanings it is helpful to refer back to the UNESCO definition quoted at the start of this chapter. All of the elements in this definition align with the emancipatory understanding of literacy as a concept, as already presented. However, as a concept with a long history and a term with wide usage, its meanings when used in the other examples given are narrower than the UNESCO definition. In everyday usage, literacy is often taken to mean simply the ability to read and write. For many people it is also associated with school. In its usage 
as a compound term, literacy often acts as a metaphor for technical or operational skills, with the widespread emergence of 'digital literacy' policy initiatives as an example (Bassett et al., 2013; Knobel \& Lankshear, 2007). While these usages reflect some elements of the UNESCO definition, none of them encompass an understanding of literacy's potential to enable social change and, in this way, they indicate a traditional implicit understanding of literacy, one that derives from the 'autonomous model' (Street, 1984). This sits in direct opposition to the emancipatory understanding of literacy, a contradiction that has fuelled much academic debate (Cook Gumperz, 2006; Gee, 2015). Where the application of the emancipatory understanding of literacy has the potential to empower those affected by social inequality by positioning them and their knowledge at the centre of a process of learning and change, embedded in the traditional understanding of literacy is the notion that power lies, and remains, with those who already have it. This is a consequence of literacy's primary usage in the context of schooling, where what is taught is defined, tested, and standardized by those in positions of power (Cook Gumperz, 2006; Gee, 2015). As such, applications of this understanding of literacy are not concerned with addressing inequality in society in the emancipatory sense, even though acquiring literacy, understood in a traditional way, can indeed be empowering. Lastly, there can also be negative connotations implicit in the term literacy in its everyday usage. These have their origin in the historical reification of literacy which equated it with the well-being of society. This led to the popular belief that 'literate people are [...] more intelligent, more modern, more moral' (Gee, 2015, p. 67). The continued currency of this belief today is evident in the pejorative inference that any use of the term illiterate carries with it. Thus, having considered a range of instances where people use literacy as a term or as a concept, it can be seen that there are different notions of power embedded in different population's implicit understandings of it.

When terms do not mean the same thing to everyone, there is an impact in everyday life. This is something Bassett et al. (2013) researched empirically in the context of computer use in community organizations. The researchers were interested in, amongst other things, what uses of digital technology, and expectations of use, result from the two terms literacy and expertise. They did this through interviewing and observing both professional and new users of digital technologies within community projects that either focused on enabling marginalized groups to access digital technologies or used digital technologies to undertake cultural activities. The researchers also reviewed literacy discourses in policy documents. They found that the widely used term 'digital literacy' was not ambitious enough for under-served 
populations: the term was understood reductively as a set of actions undertaken to avoid risk and harm; it encouraged passive, not active, participation; and it did not foster any ambition in the creative use of digital technologies, focusing just on access instead. Conversely, they found that thinking with the term expertise meant that participants expected more in terms of their own digital media skills. This shows that the implicit understandings of terminology have an impact in everyday life, in this instance influencing the kinds of use, users, skills, and expectations that result.

Literacy can be understood by different populations in multiple and divergent ways, with different notions of power embedded within different understandings, and this has implications when working in the context of inequality. When associated with an emancipatory understanding, literacy is a useful concept for framing initiatives that seek to address inequality in marginalized communities. However, while widespread in certain academic fields, this understanding is not popularly shared. Instead, with a variety of other understandings of the term more common in everyday usage, those same communities might be confused, insulted, or just think that a literacy initiative is not relevant to them. At worst, literacy is a term that carries implications of the social domination that emancipatory literacy initiatives seek to counter. This is why it is important to consider alternative terms.

\section{How useful are the alternatives to literacy?}

Other academic concepts that are used for thinking about the skills and awareness needed to make sense of aspects of society include competence, skill, know-how, and expertise, so it is these that I have considered as alternatives to literacy. Like literacy, as well as being concepts, these are all also terms that are used in the everyday. Having explored why the emancipatory understanding of literacy is useful for researching social inequality, as well as the reasons that its multiple and divergent implicit meanings are problematic, two criteria emerge for assessing alternatives. Firstly, the emancipatory understanding of literacy is useful because, as a concept, it enables both researchers and populations affected by inequality to ask critical questions around power. This provides one criterion that any alternative to literacy, as a concept, should also meet. However, one of the key features of emancipatory literacy research is that it is informed by those who might be affected by the issue being researched, that is to say the research is situated in their everyday lives. This is where the term literacy, with different notions of power embedded within different understandings 
of it, has the potential to cause problems when used in public initiatives that seek to address social inequality. Therefore, the second criterion is that, as a term in everyday usage, any alternative to literacy should not cause problems as a result of differential understandings of the relationship between the term, its meanings, and the power relationships in which it is embedded and which its use seeks to address.

Competence is a concept researched primarily in educational psychology and management studies. While there is no simple definition, it can be usefully thought of as the knowledge, skills, and attitudes-or cognitive competences, functional competences, and behavioural competencies (intentional change of spelling in that last instance) respectively-that are learned at work, post-education, to meet the demands of a particular occupation (Le Deist \& Winterton, 2005). Le Deist and Winterton (2005) make the case for developing a common typology of competence across vocational education and work-based learning, as well as across occupations and locations, ultimately to promote greater transparency and mobility. However, they also note that interrogation from a sociocultural perspective of existing efforts to standardize competence, for example with certificates or assessments, or of the influence of context and culture on understandings of competence, has been neglected. From this point of view the concept of competence does not provide a useful lens for thinking about power. There is no evidence to report on the everyday usage of the term, although its antonym, incompetent, is also popularly used. It is not hard to imagine that, like the term illiterate, the inference of deficiency associated with such a term would not be welcomed by anyone at whom it was directed.

Skill is a word that, in its everyday usage, can be found describing factors that contribute to all of the other terms being considered here, and vice versa. However, it is also a concept in its own right. It has no simple definition, but it is understood as an ability, with both mental and physical dimensions, that can be applied at different levels ranging from competent at one extreme to expert at the other (Attewell, 1990). Academic interest in skill derives from thinking about where skills are situated and how they are described, acquired, transferred, and measured in relation to their value in the labour market, particularly since the advent of technology. The concept of skill is therefore used in a range of fields including economics, psychology, and sociology (Attewell, 1990; Green, 2011). It is the latter that is of interest here, as sociological research has investigated the notion of skill as a social construction highlighting gender and class inequalities in particular (Green, 2011). To my knowledge, skill has not been researched as a term in everyday usage. However, it is noticeable that literature discussing skill-related issues, in any field, uses 
the term low-skilled rather than unskilled. Like illiterate and incompetent, unskilled is a term in everyday usage that has the potential to infer a deficiency.

Know-how is a further alternative to literacy, a concept often used in management and organizational studies concerning our knowledge about using technology. One definition is 'our ability to perform skills without being able to articulate how we do them' (Collins, 1992, p. 56). It is also known as tacit knowledge and is based on a set of social skills, sitting in contrast to knowledge that can be modelled (Collins, 1992). However, while it is helpful to consider that there are different types of knowledge that go into making sense of situations, and there is acknowledgement that tacit knowledge is dependent on social context, only considering one type of knowledge will not provide insight into the full range of skills and awareness needed for making sense of data visualizations. Know-how is a concept that Pols (2014) has used to privilege patients' knowledge in the field of medical research, where traditionally it is lay people who support, rather than inform, medical knowledge. In her case study of people with severe lung disease, Pols developed the concept of 'know-Now' (2014, p. 88) — a variation on 'know-How' specifically for interpreting new situations - to explain how patients articulate the knowledge that they develop and use in their daily lives and make it transferable and useful to others. This adaptation of the concept of know-how does enable voices to be heard that usually are not. As a term, to the best of my knowledge, know-how does not have troubling notions of power embedded within it.

Expertise is the last alternative to literacy being considered here, a concept that is discussed in science and technology studies (STS) literature, in the context of public understanding of science, where the value of lay versus expert knowledge is debated. The difficulty of trying to define expertise relates to identifying and describing where the boundary lies between expert and lay knowledge (Collins \& Evans, 2002). In his case study about the interactions between scientific experts and the sheep farmers whose livelihoods were negatively impacted by the radioactive fall-out from the Chernobyl nuclear accident, Wynne (1996) found that the perspective of the scientists 'was just as socially grounded, conditional and value-laden' (p. 38 ) as that of the farmers. It is through the recognition that expertise is socially situated that the concept invites questions to be raised around power. Elsewhere, feminist STS scholars in particular have challenged male dominance over what counts as technical knowledge and expertise (Ford \& Wajcman, 2017). Research has highlighted opposing effects of implicit understandings of the term expertise when used in community projects. Bassett et al. (2013) found that the term expertise, in contrast to literacy, 
meant 'to raise the bar' (p. 28) in relation to people's expectations about their own computer skills, and in what they can produce. However, Rey-Mazón et al. (2018), reporting on three distinct community projects that had all used open-source technologies for collecting data, found that when certain people or institutions are recognized to have expertise, the value of other people's contributions to collective inquiry and knowledge is diminished, and as such the term expert was seen to 'bolster imbalances in power' (n.p.).

In summary, four concepts - competence, skill, know-how, and expertise-are alternatives to literacy which may provide a lens to think about how inequality intersects with people's abilities for making sense of their worlds. Measured against the first criterion that, as a concept, any alternative should enable those affected by inequality to ask critical questions around power, with the exception of competence, all concepts enable this. Like literacy, skill, know-how, and expertise are all acknowledged to be socially and culturally situated, a perspective which invites critical questions. However, all four alternatives can be found in most accounts of literacy. While the alternatives all relate to one or more aspects of literacy, individually they are each smaller in scope than literacy. As such, these alternative concepts may not be as useful as literacy for researching the skills and awareness needed for making sense of data visualizations in an unequal data society. Against the second criterion that, as a term, any alternative to literacy should not cause problems as a result of differential understandings of the relationship between the term, its meanings, and the power relationships in which it is embedded and which its use seeks to address, know-how seems to be the least problematic term. It does not have multiple meanings, nor does it have an antonym that infers deficiency.

\section{Conclusion}

In asking whether literacy is what we need in an unequal data society, is has been useful to consider it both as a concept and as a term, as well as thinking about four alternatives. I conclude that, as a concept, literacy is the most useful. Not only does it enable both researchers and populations affected by inequality to ask critical questions around power, it also offers the broadest scope for researching the skills and awareness needed for making sense of data visualizations in an unequal data society. However, as a term for engaging with populations, know-how provides the best alternative to literacy, not having notions of power embedded in any implicit understandings associated with it. 


\section{References}

Attewell, P. (1990). What is skill? Work and Occupations, $17(4), 422-448$. https://doi. org/10.1177/0730888490017004003

Avgerinou, M. D., \& Pettersson, R. (2011). Toward a cohesive theory of visual literacy. Journal of Visual Literacy, 3o(2), 1-19. https://doi.org/10.108o/23796529.2011.11674687

Barton, D., \& Hamilton, M. (1998). Local literacies: reading and writing in one community. London: Routledge.

Bassett, C., Fotopoulou, A., \& Howland, K. (2013). Expertise: A scoping study. Working Papers of the Communities \& Culture Network+.

Bhargava, R. (2018). Launching the Data Culture Project. Retrieved September 24, 2018 from https://medium.com/mit-media-lab/launching-the-data-cultureproject-58fc2dbbi7ed

Boy, J., Rensink, R. A., Bertini, E., \& Fekete, J. (2015). A principled way of assessing visualization literacy. IEEE Transactions on Visualization and Computer Graphics, 2o(12).

boyd, d., \& Crawford, K. (2012). Critical questions for big data. Information, Communication and Society, 15(5), 662-679. https://doi.org/10.1080/1369118X.2012.678878

Cairo, A. (2013). The functional art: An introduction to information graphics and visualization. Berkeley, CA: New Riders.

Card, S. K., Mackinlay, J. D., \& Shneiderman, B. (1999). Readings in information visualization: Using vision to think. San Francisco, CA: Morgan Kaufmann Publishers.

Collins, H. M. (1992). Replicating the TEA-Laser: Maintaining scientific knowledge. In: H.M. Collins (Ed.), Changing order: Replication and induction in scientific practice (2nd ed.). (pp. 51-78). Chicago and London: The University of Chicago Press.

Collins, H. M., \& Evans, R. (2002). The third wave of science studies: Studies of expertise and experience. Social Studies of Science, 32(2), 235-296. https://doi. org/10.1177/0306312702032002003

Cook Gumperz, J. (Ed.). (2006). The social construction of literacy (2nd ed.). Cambridge: Cambridge University Press.

Coughlan, S. (2018, September 7). Kate Winslet warns of 'shame' of illiteracy. BBC News. Retrieved from https://www.bbc.co.uk/news/education-45435973

D'Ignazio, C., \& Bhargava, R. (2016). DataBasic: Design principles, tools and activities for data literacy learners. The Journal of Community Informatics, $12(3), 83-107$.

Department for Digital, Culture, Media \& Sport. (2017). 2. Digital skills and inclusiongiving everyone access to the digital skills they need. Retrieved August 16, 2018 from https://www.gov.uk/government/publications/uk-digital-strategy/2-digitalskills-and-inclusion-giving-everyone-access-to-the-digital-skills-they-need 
Department for Education. (2014). National curriculum in England: Framework for key stages 1 to 4. Retrieved September 8, 2018 from https://www.gov.uk/government/ publications/national-curriculum-in-england-framework-for-key-stages-1-to-4/ the-national-curriculum-in-england-framework-for-key-stages-1-to-4

Duhaney, D. (2018). Data literacy_improving conversations about data. Retrieved August 16, 2018 from https://dataingovernment.blog.gov.uk/2018/o2/21/ data-literacy-improving-conversations-about-data/

Eubanks, V. (2018). Automating inequality: How high-tech tools profile, police, and punish the poor. New York: St. Martin's Press.

Feigenbaum, A., Thorsen, E., Weissmann, D., \& Demirkol, O. (2016). Visualising data stories together: Reflections on data journalism education from the Bournemouth University Datalabs Project. Journalism Education, 5(2), 59-74.

Few, S. (2013). Data visualization for human perception. In: Interaction Design Foundation (Ed.), The encyclopedia of human-computer interaction (2nd ed.). Retrieved July 13, 2017 from https://www.interaction-design.org/ literature/book/the-encyclopedia-of-human-computer-interaction-2nd-ed/ data-visualization-for-human-perception

Ford, H., \& Wajcman, J. (2017). 'Anyone can edit', not everyone does: Wikipedia's

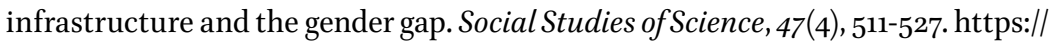
doi.org/10.1177/0306312717692172

Freire, P. (1996). Pedagogy of the oppressed. London: Penguin Group.

Gee, J. P. (2015). Social linguistics and literacies: Ideology in discourses (5th ed.). New York: Routledge.

Gitelman, L., \& Jackson, V. (2013). Introduction. In: L. Gitelman (Ed.), Raw data is an Oxymoron. (pp. 1-14). Cambridge, MA: MIT Press.

Gray, J., Bounegru, L., Milan, S., \& Ciuccarelli, P. (2016). Ways of seeing data: Toward a critical literacy for data visualizations as research objects and research devices. In: S. Kubitschko \& A. Kaun (Eds.), Innovative methods in media and communication research. (pp. 227-251). Cham: Palgrave Macmillan.

Gray, J., Gerlitz, C., \& Bounegru, L. (2018). Data infrastructure literacy. Big Data \& Society, 5(2), 1-13. https://doi.org/10.1177/2053951718786316

Green, F. (2011). What is skill? An inter-disciplinary synthesis. Centre for Learning and Life Chances in Knowledge Economies and Societies. Retrieved September 10, 2018 from https://www.llakes.ac.uk/sites/default/files/Green\%20-\%2oWhat\%20 is\%20Skill\%20-\%2ofinal.pdf

Kennedy, H. (2018). Living with data: Aligning data studies and data activism through a focus on everyday experiences of datafication. Krisis, 1, 18-30.

Kennedy, H., \& Hill, R. L. (2016). The pleasure and pain of visualizing data in times of data power. Television \& New Media, 18(8), 769-782. https://doi. org/10.1177/1527476416667823 
Kennedy, H., \& Hill, R. L. (2017). The feeling of numbers: Emotions in everyday engagements with data and their visualisation. Sociology, 52(4), 830-848. https:// doi.org/10.1177/0038038516674675

Kennedy, H., Hill, R. L., Allen, W., \& Kirk, A. (n.d.). Original seeing data research-Seeing data. Retrieved September 24, 2018 from http://seeingdata. org/original-seeing-data-research/

Knight, M. (2018). A data literacy scale? Retrieved August 16, 2018 from https:// digitalblog.ons.gov.uk/2018/04/05/a-data-literacy-scale/

Knobel, M., \& Lankshear, C. (Eds.). (2007). A new literacies sampler. New York: Peter Lang. Le Deist, F. D., \& Winterton, J. (2005). What is competence? Human Resource Development International, 8(1), 27-46. https://doi.org/10.1080/1367886042000338227

Lee, S., Kim, S. H., Hung, Y. H., Lam, H., Kang, Y. A., \& Yi, J. S. (2016). How do people make sense of unfamiliar visualizations?: A grounded model of novice's information visualization sensemaking. IEEE Transactions on Visualization and Computer Graphics, 22(1), 499-508.

Letouzé, E., Bhargava, R., Deahl, E., Noonan, A., Sangokoya, D., \& Shoup, N. (2015). Beyond data literacy: Reinventing community engagement and empowerment in the age of data. Data-Pop Alliance White Paper Series. Data-Pop Alliance (Harvard Humanitarian Initiative, MIT Media Lab, \& Overseas Development Institute) \& Internews.

Noble, S. U. (2018). Algorithms of oppression: How search engines reinforce racism. New York: New York University Press.

Concept [Def. 2] . (2018). In: OED Online. Oxford University Press. Retrieved October 10, 2018 from http://www.oed.com/view/Entry/38130?rskey=tıpjzZ\&result=1

Term [Def. 11a]. (2018). In: OED Online. Oxford University Press. Retrieved October 10, 2018 from http://www.oed.com/view/Entry/199409?rskey=eGVZob\&result=1

Pols, J. (2014). Knowing patients: Turning patient knowledge into science. Science, Technology, \& Human Values, 39(1), 73-97. https://doi.org/10.1177/0162243913504306 Potter, W. J. (2005). Media literacy (3rd ed.). Thousand Oaks, CA \& London: Sage. Rey-Mazón, P., Keysar, H., Dosemagen, S., D’Ignazio, C., \& Blair, D. (2018). Public lab: Community-based approaches to urban and environmental health and justice. Science and Engineering Ethics, 24(3), 971-997.

SCONUL. (2011). The SCONUL seven pillars of information literacy. SCONUL Working Group on Information Literacy. Retrieved April 15, 2017 from https://www. sconul.ac.uk/sites/default/files/documents/coremodel.pdf

Street, B.V. (1984). Literacy in theory and practice. Cambridge: Cambridge University Press.

UNESCO. (2005). Aspects of literacy assessment: topics and issues from the UNESCO Expert Meeting. Retrieved from http://unesdoc.unesco.org/ images/o014/001401/140125eo.pdf 
Vuorikari, R., Punie, Y., Carretero, S., \& Van Den Brande, L. (2016). DigComp 2.0: The digital competence framework for citizens. Update Phase 1: The Conceptual Reference Model.JRC Science for Policy Report. Luxembourg Publication Office of the European Union.

Ware, C. (2012). Information visualization: Perception for design (3rd ed.). Waltham, MA: Morgan Kaufmann.

Wynne, B. E. (1996). Misunderstood misunderstandings: Social identities and public uptake of science. In: A. Irwin \& B. E. Wynne (Eds.), Misunderstanding science?: The public reconstruction of science and technology. (pp. 19-46). Cambridge: Cambridge University Press.

\section{About the author}

Lulu Pinney is a PhD student in the Department of Sociological Studies at the University of Sheffield. She is researching non-experts' experiences of working with data and its visualization in community organizations. She comes to this research from professional practice where she designed data visualizations as well as running introductory data visualization training. 
